\title{
International and specification of the artistics of artistics
}

\author{
Jahongir Mamatqosimov \\ Professor, Art and culture state university of Uzbekistan
}

\begin{abstract}
This article contributes to the different distribution of fiction, as well as the scientific and theoretical and creative aspects of working with one of the creative processes. Assistance is provided on the types of scenarios, the creative stages of working on the artwork. Abbreviations for the use of methods of assurance of the manufacture of artworks.
\end{abstract}

Keywords: literature, fiction, dramatization, creative process, spectral, sectional distribution, directing, director.

\section{INTRODUCTION}

Choosing a repertoire is an important process in the production of a play, and a dramatic work can be taken as a repertoire or a non-dramatic work of art. Works that are written in non-dramatic form are first put into the installation and then the process begins. The process requires twice as much talent and effort as the director.

The installation is a masterpiece and has its own history and specifics. The installment process is a full-scale dramatic work of artistic and spiritual value, based on certain principles.

Annotated Dictionary of the Uzbek language reads: "Instsenirovka (Latin in- - to + ssena scene) Scenic transformation, staging, and staging" [5 -P. 216].

Annotated Glossary of Cultural and Art terms states that "Instsenirovka is a dramatic work of dramatic non-dramatic literary work for theatrical stage, radio, and television, and as a consequence [3]. P. 58].

\section{MAIN PART}

Famous director and educator F.Ahmedov The word "Instenirovka" is derived from Latin, which means that something can be changed into a scene, to adapt it to a stage. In the installment, the work is customized to the stage, moving as much as possible into a monologue and dialogue, ensuring that the event moves in the same place. Of course, it is necessary to ensure that the development of events will continue in the compositional direction. In this case, the contradictions in the show, the nodes, the culmination, and the solution must be identified in the director's analysis. "[2] -P. 200].

Although the opinions of the experts and the definition in encyclopaedias and dictionaries have the same meaning in common, we have tried to generalize the concepts.

Instsenirovka is a dramatic work of dramatic non-dramatic art and social-historical, publicist, archival documents and works of folk art.

Based on many years of pedagogical activity and practice, we can classify the scenarios in terms of writing.

Simple scripting - where dramatic formats of a story or novel or a small amount of historical documents are presented. For example, the "Pomegranate", "Patient", "The Thief" by A. Kakhkhor for the student scene, the stories of U. Umarbekov "Land Sleep", "Bulgarian Songs", "The Last Victim of War" by H.Olimjon Excerpts from the stories "Aigul and Bakhtiyor", "Mukanna", poetic poems by E.Vahidov, "Shum boy" by G.Gulyam, "Shaytanat" by T.Malik, "People walking in the moon", "My father's fields". , A. Kadiri's "The Past Days", "Scorpio from Mehrob", "Night and Day" by Chulpon, "A Day to the Century" by Ch.Aytmatov excerpts from the novel, small in size, this process is now engaged staged for the first step. Collective Scenario - a series of short stories or small historical documents, or works of one or more writers and poets, in a coherent dramatic fashion. For example, the play "The Ancestors of the Past" (directed by Valijon Umarov), staged at the Uzbek National Academic Drama Theater in honor of the 2003 writer Gafur Ghulam's 100th anniversary, is staged by famous playwright Usman Azim. There 
are also numerous plays based on comic poems about Matmusa, which are included in the poetry collection of E.Vahidov's poems "Wise Village," on the stage of students of the State Institute of Arts and Culture of Uzbekistan. Also, based on stories from Kalila and Dimna, scenarios that reflect the peculiarities of the ancient Indian people have been repeatedly refined for the student scene. A number of literary and artistic scenarios, directed at improving the students' speech, are based on the work of the author U. Hashimov "Books in the field of the notebook."

Complex scenario - in which a novel or narrative is selected, a large-scale and socially significant historical-publicist, archive document, and the events in it are transformed into a dramatic masterpiece. For example, most of the theatrical performances have been re-enacted and re-staged several times by A. Kadyri's "Past Days", "Scorpio from Mehrob", "Night and Day" by Chulpon, "Star Nights" by P. Kadyrov, "The Age of the Generals" These are novels and novels like Navoi, D.Phone's "Prisoner of If," G. Marquez's "A Century of Loneliness", R. Guntekin's "Choliqushi", and N. Bukhi's execution of socially significant historical-publicistic works. of the phrase. Film and radio versions of these and other works have also been edited in many languages.

Reconstruction of dramatized non-dramatic literary works and socially important historicalpublicist, archival documents, samples of folk art, that is, dramatic work, is a creative process.

Read selected work. Everyone's thinking and understanding are different, and one can understand a piece from one read and another from a hundred. At this stage, the selected work will be read over and over again by the applicant (the author) until he or she has fully understood the essence. The applicant must have a deep understanding of each event, real understanding of the character and life of the characters, "reason", "sympathy" with the characters. In short, it is important that the work is fully mastered.

Studying the creative activity of the author. The applicant's life and work should be widely studied. This is because the author's time and place of living, the way and the purpose of writing this work also determine the social value of the work. The applicant must familiarize himself / herself with all the masterpieces of the author's writing language and style. Future scripting should speak the language of the original work and preserve the author's creative style.

Analysis of the social significance of the selected work. The analysis of the period and the sociopolitical processes of the selected work reveals the purpose, ideas, educational and aesthetic and sociopolitical significance of the work. The applicant should also take into account the wide discussion of the work in the art council.

Split the selected work. This process is mainly through the production of large-scale works or novel installations. The main reason for this is the separation of the work by the author into different parts and chapters, which means that the future installment will be the scene. On the one hand, events occurring in one place can be separated into separate, logically related events, and events occurring at the same time. It depends on the creative skills of the applicant.

Installation of split sections. The sections that are selected by the applicant are analyzed and read more closely. The individual installation of each piece ensures the artistic value of this piece so that no small details can be ignored. A character may be added or removed without affecting the purpose of the work. In fact, some aspects may be removed without affecting the original work.

For example ... the creative team of the theater and director A. Ginszburg correctly understood the essence of the writer Dib, working some images and adding some new ones. This bold exploration allowed life to be displayed in more authentic, more vibrant colors than in the novel. -B. 33]. ... The image of Muhammad has just been added to the script. This image depicts the image of a fictitious man, whose life is full of confusion and hesitation. Muhammad willfully betray his neighbors, gradually his people, and will hand over patriots to the French police because of his will. However, Muhammad would not last this treachery because the people would open his eyes like a mosquito. Finally, he understands his crimes, confesses, and goes back to the right way and does not separate from the people. People's Artist of Uzbekistan Amin Turdiev managed to create this image for the best. -P. 35].

Generalization of separated sections. This process is one of the final parts of turning a selected work into a dramatic one. At the same time, the separated pieces are arranged sequentially in essence. At the same time, the events may be replaced in a way that is not contrary to the substance of the original 
work; The most important task in this process is to make sure that the finished installations comply with the laws of playwriting and that the composition of the composition be carefully analyzed.

For example, in 2013 at the Uzbek National Academic Drama Theater, a performance based on A. Kady's novel "Past Days" begins with a meeting of Otabek and Silver on the river. However, the story is told in Chapter 11 (by screenwriter E.Hushvaktov and director M.Azimov).

\section{SUMMARY}

The finished scenario should be repeated by the applicant again. It is necessary to ensure the literary language norms, to prevent the author's "language" and style violations, to re-examine the socio-political and educational importance of the script, and to thoroughly analyze the compositional structure of the work. At this stage, the installation is called, so the script can be left unchanged or renamed. For example, R. Tagore's novel Halokat, played in 1956 at the Uzbek National Academic Drama Theater, was staged and titled "Girl on the Gang River" (screenwriter and director AO Ginzburg). Also in the same theater, the novel "The Past Days" by A. Kadyri was staged by playwright E. Khushvaqtov in 2013, preserving the title "Past Days" (directed by M. Azimov), with the play "Otabek and Kumushbibi" at the Mukimi Musical Theater. (directed by J. Dzhabbarov and stage director R. Madiyev). R.Guntekin's novel "Choliqushi" was staged in the Uzbek National Academic Drama Theater in 2009 under the title "Farida's Heart Notebook" (by F. Usmanova, directed by M. Abdullaeva).

$>\quad$ It is also useful to review the playwriters and playwriters before making the final installment.

$>$ Installation requires great knowledge and thinking, imagination and hard work from the author. This is because the work has the same artistic value as the finished work. So no matter who is writing a screenplay, a creative person who can properly analyze what is happening in the community, has a deep understanding of cultural life, has the knowledge, skills and abilities in literature and drama theory, and most importantly, loves literature. should be.

$>$ Instenialization is not just an accidental need for good drama, it is a necessary phenomenon that is directly related to spirituality, artistic taste and literacy. -P. 11].

$>$ In modern art, installations are widely used for screen and stage art as well as for field performances. In particular, the importance of screenplay is also important in the management of public holidays. Because almost all of the material selected for the holiday can be in a literary way, or as an archive document. Bringing these materials to the stage in such a way can make the viewer feel almost invisible, or the celebration can be dull. Therefore, the whole material is collected and put into an instrumentation by artistic means. The material is staged based on the essence of the material.

The following methodical recommendations are given for improving the artistic level of drama and ensuring that it fully meets the requirements of playwriting and further improves students' attitude to fiction:

- further improvement of the Master-student traditions in the field;

- strengthening reading of fiction;

- integration of theory and practice;

- organization of master classes, online meetings with experienced local and foreign experts.

It should be noted that any work created as a result of the targeting of any literary work cannot be considered a scenario. Water-based, dramatic, aesthetic, and aesthetic-important installations are guaranteed criteria for the performance or artistic quality of the play.

\section{REFERENCES}

1. Abdurasulov Sh. Literature, stage, installation. - Tashkent: National Library of Uzbekistan named after Alisher Navoi, 2015.

2. Ahmedov F.E. Basics of Mass Holidays Directorate. - Tashkent: Communications, 2008.

3. Explanatory dictionary of terms of culture and art. Edited by B.Sayfullaev. - Tashkent: Gafur Gulom Publishing House, 2015.

4. Tursunov T. Scene and time. - Tashkent: The New Generation, 2007.

5. Explanatory dictionary of the Uzbek language. The letter "I". Edited by A. Madvaliev. Tashkent: State Scientific Publishing House "National Encyclopedia of Uzbekistan", 2003 